\title{
Condiciones para el desarrollo de granjas perleras y producción de perlas: estado del arte, potencial y perspectivas
}

\author{
Conditions for development of pearl farms and production of pearls: \\ state of the art, potential and perspectives
}

\section{Mario Monteforte ${ }^{1}$ y Micheline Cariño ${ }^{2}$}

${ }^{1}$ Centro de Investigaciones Biológicas del Noroeste, S.C. (CIBNOR), Av. Instituto Politécnico Nacional No 195, Col. Playa Palo de Santa Rita, La Paz, Baja California Sur, CP 23090, México. montefor04@cibnor.mx

${ }^{2}$ Departamento de Humanidades, Universidad Autónoma de Baja California Sur (UABCS), Km. 5.5 Carretera al Sur, Col. El Mezquitito, La Paz, Baja California Sur, CP 23080. México. marthamichelinecarino@gmail.com

\begin{abstract}
Pearl farms with pearl oysters, abalones, freshwater pearl mussels, and some snails and bivalves having attractive shell, stand out for their general feasibility and commercial value of products. To achieve acceptable profitability, technique-operational validation and assimilation are required in real conditions into multivariate scenarios where the plans sometimes present radical differences even at spot-scale. Pearl culture appears as added value that depends on the input of viable juveniles and efficient management of production cycles. In this work the art of pearl culture is presented as a skill to be acquired from practice and training, which is accessible to any producer that accomplished continuity in the farming procedures. The historical development of pearl culture, from the ancient Buddha Pearls to pearls in vitro, has happened in linear events through improvements of manual and mechanical means. The wide diffusion of pearl farms relies on episodes of environmental history throughout special coincidences in the regions. The review of these transformation processes, based on study and interpretation of evidences and evaluation of potentials in the $21^{\text {st }}$ century, projects about mollusk farming for shells, nacre or pearls, are analyzed under objective arguments in terms of advantages, disadvantages and prospects to access on one of the most sensitive luxury markets, for its characteristics of natural wealth, dependence on regional and global dynamics and intrinsic difficulties to start and maintain a high-risk technological project, with unpredictable results.
\end{abstract}

Key words: Pearl-bearing mollusks, pearl farms, feasibility analysis, regional development, business plans, commodities market

Resumen.- Las granjas productoras de nácar y perlas con ostras perleras, abulones, náyades, y algunos caracoles y bivalvos de concha atractiva, destacan por su factibilidad general y el valor comercial de los productos. Para alcanzar rentabilidad aceptable se requiere un proceso de validación técnica-operativa y asimilación en condiciones reales, que aplica en escenarios multivariados donde la planeación presenta diferencias radicales incluso a escala puntual. La perlicultura aparece como un valor agregado que depende del suministro de juveniles viables y manejo eficiente de los ciclos de producción. En este trabajo se presenta al arte de inducir perlas como una habilidad práctica con entrenamiento accesible para cualquier productor que logre continuidad en los procesos de cría. El desarrollo histórico de la perlicultura, desde las milenarias Perlas de Buda a las perlas in vitro, se ha dado en eventos lineales a través del perfeccionamiento manual y de medios mecánicos. La gran difusión de las granjas perleras se apoya en episodios de historia ambiental a través de particulares coincidencias en las regiones. El examen de estos procesos de transformación, estudio e interpretación de evidencias, y evaluación de los potenciales en el siglo XXI, son analizados bajo argumentos objetivos en términos de ventajas, desventajas y perspectivas, de uno de los mercados suntuarios más sensibles por sus características de riqueza natural, dependencia a dinámicas regionales y globales, y dificultades que implica poner en obra un proyecto tecnológico de alto riesgo con resultados impredecibles.

Palabras clave: Moluscos perleros, granjas de perlicultura, análisis de factibilidad, desarrollo regional, plan de negocio, mercado suntuario 


\section{INTRODUCCIÓN}

La información científica y técnica para operar una granja perlera -casi con cualquier molusco susceptible de producir perlas- se encuentra sistematizada desde hace más de un siglo y disponible en las bases de datos bibliográficos. Solamente en temas relacionados con ostras perleras el número de publicaciones formales sobrepasa las 2,000 (Gervis 1991, Cariño \& Monteforte 2006, Southgate \& Lucas 2008, Monteforte \& Bervera 2011); con la suma en abulones, mejillones perleros o náyades y otros, serían miles adicionales. La abundancia y diversidad de datos, especialmente su utilidad en condiciones reales, varía dependiendo de cada especie o región. Sin embargo, los procedimientos de cría en laboratorio y/o en campo tienen similitudes entre especies emparentadas, cambiando relativamente poco el manejo de instalaciones y artes de cultivo, aunque haya diferencias considerables en niveles de conocimiento, logística y eficiencia operativa en función de cada especie y de la idiosincrasia de cada localidad, así como en el tamaño y complejidad de los proyectos. Esto significaría comparar cultivos de gran amplitud, desde una granja piloto-demostrativa de cultivo extensivo o de tipo recolecta-encierro, a un sistema cerrado de mono o policultivo industrial usando biotecnología nutricional e ingeniería genética, considerando la extensa gama de infraestructura, equipo y materiales que ofrece el mercado acuícola para sostener un determinado proyecto. No obstante, la perlicultura es una tecnología hoy accesible al público y relativamente sencilla, por lo que la proporción económica que ocupa el proceso de apropiación de este conocimiento en la planificación de una granja perlera, es mucho menor a lo que cobran ciertos supuestos expertos por transferir el 'secreto'.

Si bien en este trabajo se pretende desmitificar el concepto exclusivista de las granjas perleras y la perlicultura, también se intenta presentar un análisis crítico sobre las condiciones y dificultades que confrontaría un nuevo productor al fundamentar un plan de negocios en el mercado suntuario moderno, especialmente el de nácar y perlas. La factibilidad técnica en algunas especies, con diferentes grados de dominio o perfeccionamiento de diferentes modalidades de producción, y el virtual positivo de las expectaciones financieras, sin duda son un tentador aliciente. Sin embargo, el éxito no se mide en número de perlas sino con base en estrategias de mercadotecnia donde rigen exigentes estándares de calidad en el manejo de las granjas y las características de los productos (Muller 2005, 2009; CIBJO 2010). Tan simple como aprender las manipulaciones para inducir perlas en los moluscos perleros, un presunto emprendedor y/o actuales productores debieran considerar los trabajos experimentales y antecedentes históricos de este negocio acuícola: los indicadores de éxito son rigurosos e inflexibles en todas las etapas (niveles técnicos/ económicos de eficiencia y de asimilación práctica, mortalidad acumulada, crecimiento, estado de salud, calidad de nácar/carne, características del nácar y las perlas como tamaño, color, oriente, etc.), y la validación técnica-operativa de los ciclos de producción implica riesgos e imprevistos, costos y tiempo, que no cualquier interesado puede enfrentar, solventar o resolver por sí solo. Se cuenta hoy con tecnologías demostradas, ejemplos de éxito y diversos niveles de perfeccionamiento de cultivo y perlicultura en numerosos moluscos perleros, por lo que los indicadores financieros clásicos tienden a minimizar las condiciones reales. Considerando esta premisa, las dificultades propias al manejo productivo de estos animales, adquieren otro tipo de dimensiones donde la perlicultura representa un valor agregado totalmente dependiente de la eficiencia en el proceso completo de cría.

La línea de investigación que corresponde a este trabajo parte del interés, tanto académico como empresarial, que se ha mantenido constante por diferentes grupos y entidades en el mundo, en ejercicio o en deseo de iniciar una aventura en el dominio de los moluscos perleros. La argumentación de este estudio apunta hacia 3 objetivos estrechamente interrelacionados: 1) conocer el entorno general de los moluscos perleros como actores en la historia de las sociedades y el desarrollo tecnológico; 2) discutir conceptos, estado de conocimiento y situación mundial, mediante un examen crítico sobre la evolución y representación de las granjas perleras, y 3) con base en la evaluación de potenciales, inferir las perspectivas de este particular mercado suntuario en el siglo XXI.

En parte, un apretado compendio de eventos y coincidencias, una diagnosis de fortalezas y debilidades, este trabajo aborda el estudio de los moluscos perleros y sus diferentes modalidades de granja en un marco global examinando su incidencia en cierto tipo de escenarios cuya dinámica en espacio, tiempo y actores puede variar hasta escala local. El mensaje entrelíneas en la estructura de esta revisión se dirige en especial a valorar la situación del territorio al sur de la frontera estadounidense hasta Tierra del Fuego, considerando que el sub-aprovechado potencial perlero de esta amplia región empieza a cobrar nuevo interés por parte de grupos académicos y 
empresariales, tanto con moluscos marinos como dulceacuícolas.

\section{ORIGEN Y DESARROLLO DE LAS TECNOLOGÍAS}

La historia ambiental de las regiones perleras presenta diferencias -algunas radicales- entre episodios particulares, por ejemplo los de índole geográfico discriminan a nivel de especies y regiones, así como en aspectos sociales, políticos, económicos, científicos y tecnológicos, hasta étnicos, culturales y de identidad local. La evolución de la pesca hacia el cultivo se integra así durante miles de años en los perfiles de su relación con las sociedades, desde la escala regional (zonas pesqueras, manejo del recurso, formas de comercialización, etc.) a la puntual (tipos de granja, modalidades de operación y tecnologías de cultivo y perlicultura, etc.) (Cariño \& Monteforte 2006). El estudio de estos pasajes y transiciones ha colmado el quehacer de la investigación en áreas multidisciplinarias y multisectoriales generando gran cantidad de información en todo tipo de media, hoy disponible vía internet. Es un interés común el valor económico que se les adjudica a los moluscos perleros: concha, perla, carne en algunas especies, su capacidad de ser cultivadas en varias modalidades, su respuesta al ser inducidas manualmente con herramientas y estímulos mecánicos para la formación de perlas. De hecho la perlicultura aprovecha la capacidad natural de las especies para formar concha (nácar/aragonita o calcáreo de color). Bajo ciertos estímulos (Bell 2006, Taylor \& Strack 2008), los animales a veces responden formando protuberancias, gránulos o ampollas de 'concha' enquistados en membranas viscerales o adheridos a la cara interna de la concha (e.g., gastrópodos malacófagos pueden hacer perforaciones, así como el dátil de mar Lithophaga spp.; poliquetos barrenadores, como Polydora spp. y Boccardia spp. practican galerías en la cara interna; la fijación de esponjas como Cliona spp. y Halycliona spp., y algunos percebes Chthamalus spp. y Balanus spp. también pueden provocar granulaciones). De tal manera se forman tapones de tipo ampolla, asperezas y relieves, redes de galerías nacaradas, o singulares objetos como el esqueleto nacarado de un pez (Encheliophis dubius) en una valva de Pinctada mazatlanica, la pinza de Cancer (magister? antenarius?) recuperada en un ejemplar de Haliotis rufescens, la perla Peregrina.

En algún monasterio Budista en la zona de los grandes ríos de China, se comprendió por primera vez cómo inducir la formación de perlas, iniciandose así la tecnología acuícola quizá más antigua del mundo. Según diferentes autores, el origen de la perlicultura se ubicaría entre el siglo V A.C. y la primera década del siglo D.C. Las Perlas de Buda se producían implantando ${ }^{1}$ figurines fabricados en piedra, porcelana, madera, marfil, plomo, etc., en las valvas de las náyades o mejillones perleros, Hyriopsis cumingii y Cristaria plicata, tal vez bajo modalidad de recolecta-encierro. A medida que noticias y objetos del Celeste Imperio fluían hacia Europa, el descubrimiento de estas perlas motivó en los 1790s a Carl Linnaeus para hacer los primeros ensayos de perlicultura en Unio pictorum, una de las grandes náyades europeas. Se puede apreciar la ingeniosa adaptación que hizo Linnaeus sobre la técnica china en las colecciones de la Linnaean Society of London. Casi un siglo más tarde, Louis Boutan consiguió producir perlas 'Mabé' en la madreperla de las islas Tuamotu, Pinctada margaritifera cumingii, y en el abulón europeo, Haliotis tuberculata (Boutan 1894).

Las granjas perleras nacerían poco tiempo después con 4 experiencias que son clave en la conformación de esta industria:

1. William Saville-Kent en Thursday Island, Australia (1895-1905), con la madreperla gigante, $P$. maxima, en modalidad de recolecta-encierro a pequeña escala. Se le reconoce como el verdadero inventor de la cirugía para perla libre nucleada, indebidamente conocida como la maniobra 'Mise-Nishikawa' que fue patentada por Kokichi Mikimoto en situación controvertida (Cariño 1996, George 2008, Taylor \& Strack 2008, Monteforte \& Cariño 2012).

2. Gastón Vives y la Compañía Criadora de Concha y Perla en Bahía de La Paz, México (1902-1914), con la madreperla P. mazatlanica, primer desarrollo de cultivo extensivo a la mayor escala hasta ahora conocida (10 millones de madreperlas anualmente). El principal producto comercial era la concha, de alta demanda en la Europa de aquella

${ }^{1}$ En el lenguaje técnico de la perlicultura, implante significa adherir -mediante varias opciones mecánicas- una media-esfera o forma de diversas simetrías y/o materiales a la cara interna de valvas o concha en sus respectivos casos. Mediante implante se producen Mabé y perlas-icono. La técnica de perla libre es una cirugía con instrumentos especiales para inserción de esferas y/o trozos de manto en los tejidos blandos de un molusco perlero (manto, gónada, vísceras). Mediante esta cirugía se produce perla libre no-nucleada (Biwa, Kechi, 'perlas de arroz') y perla libre nucleada (South Seas, Black Pearls, Akoya, Zhuji, estas últimas son las perlas multicolores nucleadas de China con producción industrial de híbridos Hyriopsis schlegeli x H. cumingii (Zuhui \& Huaping 2010) 
época para la industria botonera y de incrustación. Las perlas eran de incidencia natural, numerosas y de excelente calidad, gracias a la alta densidad y buenas condiciones de cultivo. Las instalaciones de la empresa fueron saqueadas y destruidas en 1914 víctimas colaterales de la Revolución Mexicana, cesando con esto el considerable aporte larvario de la granja para el repoblamiento de los bancos naturales (Cariño \& Monteforte 1999).

3. Cyril Crossland en Dongonab Bay, Sudán (1907-1922) con $P$. margaritifera erythrensis en su empresa, Pearl Shell Company. Probablemente retomando la experiencia de Vives en La Paz, Crossland adaptó sus propias técnicas logrando cosechar 4 millones de madreperlas poco antes de que el gobierno sudanés requisara las instalaciones. En esta granja, además de comercializar la concha, se hizo perlicultura de Mabé a pequeña escala aplicando la antigua experiencia china, y no se descarta que Crossland haya probado cirugías para inducir perla libre (Cariño \& Monteforte 2006, 2009).

4. En 1928-1930 en el lago Biwa, Japón, con la náyade perlera entonces endémica, Hyriopsis schlegelii. En la literatura se menciona a Masayo Fusia² (científico investigador en Pinctada martensii) como el primero en desarrollar la cirugía para inducir perlas 'Biwa' comercialmente.

\section{Evolución De LAS GRANJAS PERLERAS Y LA PERLICULTURA}

La historiografía de cómo estos conocimientos fundadores se desarrollaron hasta conformar la industria acuícola más rentable del mundo, comprende una extensa crónica donde se empalman procesos, personajes y escenarios coincidentes, a la par de un intenso quehacer científico y tecnológico de casi 100 años que desde los 1950s ha sustituido completamente los azares de la pesca con granjas de cultivo, y la explotación de los pescadores indígenas con técnicos entrenados. Las tecnologías de cultivo y perlicultura de estos pioneros, el alcance de su obra y el desarrollo retomado por sus sucesores en otras regiones y especies, han sido analizados en diversas obras, por ejemplo, Cariño \& Monteforte (1999, 2006, 2009), Monteforte \& Cariño 2012 y Southgate \& Lucas (2008). Resaltan eventos clave y sincronías que convergieron en divulgar el procedimiento quirúrgico de la perla libre, contribuyendo a fortalecer la instalación de granjas perleras fuera de Japón. Probablemente lo más distintivo desde tal punto de vista fue la Segunda Guerra Mundial y el consiguiente reporte de Cahn (1949), con los detalles de la tecnología japonesa de cultivo (extensivo) y perlicultura en $P$. martensii. Al mismo tiempo se abrieron y se tradujeron muchos 'archivos perleros' de publicaciones de la pre-guerra, entre estos, 11 trabajos clave (1905-1948) relacionados con estos temas que apunta Cahn (1949), además de la descripción de 65 patentes de cultivo y perlicultura registradas por Mikimoto Pearls. Posteriormente se fundó el National Pearl Research Institute en cuyo boletín (1956-1978) los científicos japoneses se dedicaron a publicar los resultados de investigaciones en ciencia y tecnología sobre el cultivo y la perlicultura en esta especie, además de avanzados estudios de genética y biotecnología. Todo con amplia información gráfica y tablas, la mayoría traducido al inglés en los resúmenes, varios en texto completo y/o las referencias bibliográficas.

En la transformación de la pesca a la tecnología acuícola consta el agotamiento mundial del recurso, la sustitución del nácar por plástico, y la aceptación de las perlas cultivadas por Mikimoto Pearls en el mercado, hasta entonces bajo la férula de capitales europeos supeditados a la pesca (Cariño 1996). Mikimoto y sus concesionarios conservaron control de la técnica de perla libre y del comercio hasta finales de los 1960s que comenzaron a prosperar tecnologías regionales de cultivo en Polinesia Francesa y Australia, extendiéndose rápidamente a India y el Indo-Pacífico. Al avanzar el perfeccionamiento en el manejo de las granjas, el aprendizaje de perlicultura en especies grandes dejó de ser controlado por los carteles japoneses ${ }^{3}$. Este aporte de lujo al mercado perlero llegó a cotizar en el orden de los billones de dólares (Fassler 1994). En el proceso de desarrollo destacan actores de primera línea en la historia de las granjas perleras, como Denis George en Australia y México; Phillipe Cabral, Terry

${ }^{2}$ El nombre y datos profesionales de Masayo Fusia son de información en internet (Coleman Douglas Pearls, London: <www.pearls.co.uk/ aboutus/aboutpearls.php?mid=1\&bpid=1>; y <www.pearlmania.com>). Sin duda la fuente de animales para la producción de perlas Biwa que Fusia u otro hayan usado en aquella época provenía de recolecta y encierro de adultos naturales.

${ }^{3}$ Aún a la fecha hay una gran inversión de capital japonés en granjas que trabajan con especies grandes. Una buena parte de la producción de perlas en Pinctada proviene de técnicos japoneses 'propiedad' de las empresas. Cabe notar que bajo estos esquemas es raro que los empresarios entrenen técnicos locales. 
Tabla 1. Principales especies de moluscos perleros marinos que se utilizan en la perlicultura, zonas de cultivo e información sobre la modalidad de cultivo y los tipos de producto. Se excluyen las náyades perleras, debido a que solamente una especie (Hyriopsis cumingii x $H$. schlegelii) es la más representativa en el cultivo de perlas de agua dulce (ver texto) / Main species of pearl-bearing marine mollusks that are used in pearl culture, cultivation areas and information on culture modalities and type of product. The freshwater naiads are excluded from this table because only one species (Hyriopsis cumingii $\times \mathrm{H}$. schlegelii) represents almost all of the production of freshwater pearls (see text)

\begin{tabular}{|c|c|c|c|}
\hline $\begin{array}{l}\text { Especie/ } \\
\text { Talla común }\end{array}$ & Zona comercial & $\begin{array}{l}\text { Modalidad de cria, } \\
\text { Talla/edad (T/E) pre-perlicultura' }\end{array}$ & $\begin{array}{l}\text { Caracteristica de perla', } \\
\text { Tiempo formación }{ }^{3}\end{array}$ \\
\hline \multicolumn{4}{|l|}{ Pteriidae } \\
\hline $\begin{array}{l}\text { Pinctada maxima } \\
280-300 \mathrm{~mm}\end{array}$ & $\begin{array}{l}\text { Myanmar, Asia del Sureste, Archipiélago Malayo, } \\
\text { Australia noroeste. Amplia dispersión }\end{array}$ & $\begin{array}{l}\text { Recolecta-encierro es la práctica más común. Algunas granjas con laboratorio } \\
\text { Repoblamiento puntual por laboratorio y cultivo extensivo } \\
\text { Mabé post-cosecha de perla libre } \\
\text { T/E 3-4 años perla libre o Mabé }\end{array}$ & $\begin{array}{l}\text { Perla libre } 14-18 \mathrm{~mm}: 4 \text { años. } \\
\text { Mabé }>20 \mathrm{~mm} \text { : aprox. } 3 \text { años }\end{array}$ \\
\hline $\begin{array}{l}\text { Pteria penguin } \\
240-290 \mathrm{~mm}\end{array}$ & $\begin{array}{l}\text { Asia del Sureste, Archipiélago Malayo, Australia } \\
\text { noreste. } \\
\text { Amplia dispersión }\end{array}$ & $\begin{array}{l}\text { Cultivo extensivo, recolecta-encierro Investigación laboratorio en Australia y Tonga } \\
\text { (Ngaluafe \& Southgate 2008) } \\
\text { T/E }>3 \text { años Mabé }\end{array}$ & Mabé $>18 \mathrm{~mm}: 3$ años. \\
\hline $\begin{array}{l}\text { Pinctada margaritifera } \\
160-200 \mathrm{~mm}\end{array}$ & $\begin{array}{l}\text { Islas e islotes del Pacifico central-occidental. } \\
\text { Amplia dispersión }\end{array}$ & $\begin{array}{l}\text { Cultivo extensivo. Laboratorio en estado experimental, no comercial } \\
\text { Mabé post-cosecha de perla libre } \\
\text { T/E } 2 \text { años perla libre o Mabé }\end{array}$ & $\begin{array}{l}\text { Perla libre } 11-16 \mathrm{~mm}: 2,5-3 \text { años } \\
\text { Mabé >16 mm: aprox. } 2 \text { años }\end{array}$ \\
\hline $\begin{array}{l}\text { Pinctada mazatlanica } \\
140-180 \mathrm{~mm}\end{array}$ & $\begin{array}{l}\text { Golfo de California } \\
\text { Puntual (La Paz y Guaymas) }\end{array}$ & $\begin{array}{l}\text { Cultivo extensivo } \\
\text { Se aprovecha poco } \\
\text { T/E } 18-22 \text { meses perla libre; }>24 \text { meses Mabé }\end{array}$ & $\begin{array}{l}\text { Perla libre } 9-13 \mathrm{~mm} 2-2,5 \text { años } \\
\text { Mabé }>16 \mathrm{~mm}: 20-22 \text { meses }\end{array}$ \\
\hline $\begin{array}{l}\text { Pteria sterna } \\
120-160 \mathrm{~mm}\end{array}$ & $\begin{array}{l}\text { Golfo de California } \\
\text { Puntual (La Paz y Guaymas) }\end{array}$ & $\begin{array}{l}\text { Cultivo extensivo } \\
\text { T/E 16-18 meses perla libre; }>20 \text { meses Mabé. }\end{array}$ & $\begin{array}{l}\text { Perla libre } 8-12 \mathrm{~mm}: 2 \text { años } \\
\text { Mabe }>14 \mathrm{~mm}: 16-18 \text { meses }\end{array}$ \\
\hline $\begin{array}{l}\text { Pteria colymbus-hirundo } \\
90 \mathrm{~mm}\end{array}$ & $\begin{array}{l}\text { Venezuela } \\
1 \text { granja experimental }\end{array}$ & $\begin{array}{l}\text { Cultivo extensivo experimental } \\
\text { T/E 12-14 meses perla libre }\end{array}$ & $\begin{array}{l}\text { Perla libre 6-9 mm: } 18-20 \text { meses } \\
\text { Mabé < } 12 \mathrm{~mm}: 10-12 \text { meses }\end{array}$ \\
\hline $\begin{array}{l}\text { Pinctada imbricata-radiata } \\
80-90 \mathrm{~mm}\end{array}$ & $\begin{array}{l}\text { Quintana Roo, México } \\
1 \text { granja demostrativa }\end{array}$ & $\begin{array}{l}\text { Cultivo extensivo, pequeña escala, incipiente } \\
\text { T/E 12-14 meses perla libre }\end{array}$ & $\begin{array}{l}\text { Perla libre 6-9 mm: } 18-20 \text { meses } \\
\text { Mabé <12 mm: 10-12 meses }\end{array}$ \\
\hline $\begin{array}{l}\text { Pinctada martensii } \\
70-80 \mathrm{~mm}\end{array}$ & Japón & $\begin{array}{l}\text { Laboratorio y extensivo } \\
\text { T/E 10-12 meses perla libre }\end{array}$ & $\begin{array}{l}\text { Perla libre 6-9 mm: } 16-18 \text { meses } \\
\text { Mabé <11 mm: 8-10 meses }\end{array}$ \\
\hline $\begin{array}{l}\text { Pinctada fucata } \\
70-80 \mathrm{~mm}\end{array}$ & India sureste & $\begin{array}{l}\text { Laboratorio y extensivo } \\
\text { T/E 10-12 meses perla libre }\end{array}$ & $\begin{array}{l}\text { Perla libre 6-9 mm: } 16-18 \text { meses } \\
\text { Mabé < } 11 \mathrm{~mm}: 8-10 \text { meses }\end{array}$ \\
\hline $\begin{array}{l}\text { Pinctada chemnitzi } \\
70 \mathrm{~mm}\end{array}$ & China & $\begin{array}{l}\text { Laboratorio industrial } \\
\text { T/E 10-12 meses perla libre }\end{array}$ & $\begin{array}{l}\text { Perla libre 6-9 mm: } 16-18 \text { meses } \\
\text { Mabe }<11 \mathrm{~mm}: 8-10 \text { meses }\end{array}$ \\
\hline \multicolumn{4}{|l|}{ Haliotidae } \\
\hline $\begin{array}{l}\text { Haliotis rufescens } \\
300 \mathrm{~mm} /\end{array}$ & $\begin{array}{l}\text { California, Baja California } \\
1 \text { granja en CA, } 1 \text { en BC }\end{array}$ & $\begin{array}{l}\text { Laboratorio, cria en tierra. Repoblamiento } \\
\text { Pesca turistica en CA, comercial en BC y BCS } \\
\text { T/E }>70 \mathrm{~mm}, 5 \text { años }\end{array}$ & $\begin{array}{l}\text { Perlicultura en ind. cultivados } \\
\text { Mabé Mrg } 10-12 \mathrm{~mm}: 24 \text { meses } \\
\text { Mabé Apx } 14 \mathrm{~mm}: 28 \text { meses }\end{array}$ \\
\hline $\begin{array}{l}\text { Haliotis fulgens } \\
230 \mathrm{~mm}\end{array}$ & $\begin{array}{l}\text { California, Baja California } \\
1 \text { granja en CA }\end{array}$ & $\begin{array}{l}\text { Laboratorio, cria en tierra. Repoblamiento } \\
\text { Pesca turistica en CA, comercial en BC y BCS } \\
\mathrm{T} / \mathrm{E}>70 \mathrm{~mm}, 4,5 \text { años }\end{array}$ & $\begin{array}{l}\text { Pericultura en ind. cultivados } \\
\text { Mabé Mrg 10-12 mm: } 24 \text { meses } \\
\text { Mabé Apx } 12-14 \mathrm{~mm}: 26 \text { meses }\end{array}$ \\
\hline $\begin{array}{l}\text { Haliotis gigantea } \\
80-200 \mathrm{~mm}\end{array}$ & $\begin{array}{l}\text { Japón, Corea } \\
\text { 1-2 granjas en Japón, demostrativo. En Corea } \\
\text { tuvo poca duración }\end{array}$ & $\begin{array}{l}\text { Laboratorio, cria en tierra. Repoblamiento } \\
\text { Veda permanente } \mathrm{T} / \mathrm{E}>70 \mathrm{~mm}, 4,5 \text { años }\end{array}$ & $\begin{array}{l}\text { Perlicultura en adultos }>160 \mathrm{~mm} \text { (talla legal) } \\
\text { Mabé Mr: } 18-20 \mathrm{~mm}: 36 \text { meses } \\
\text { Mabé Apx } 20-22 \mathrm{~mm}: 40 \text { meses }\end{array}$ \\
\hline $\begin{array}{l}\text { Haliotis rubra } \\
200 \mathrm{~mm}\end{array}$ & $\begin{array}{l}\text { Australia, Tasmania } \\
\text { Dos o tres experiencias en total de corta duración }\end{array}$ & $\begin{array}{l}\text { Laboratorio, cria en tierra y mar } \\
\text { Repoblamiento. Pesca turistica } \\
\mathrm{T} / \mathrm{E}>70 \mathrm{~mm}, 4,5 \text { años }\end{array}$ & $\begin{array}{l}\text { Perlicultura en adultos }>160 \mathrm{~mm} \text { (talla legal) } \\
\text { Mabé Mrg } 18-20 \mathrm{~mm}: 36 \mathrm{meses} \\
\text { Mabé Apx } 20-22 \mathrm{~mm}: 40 \text { meses }\end{array}$ \\
\hline $\begin{array}{l}\text { Haliotis midae } \\
200 \mathrm{~mm}\end{array}$ & $\begin{array}{l}\text { Sudáfrica. Hay datos de un par de cosechas } \\
\text { demostrativas por una granja }\end{array}$ & $\begin{array}{l}\text { Laboratorio, cria en tierra. Repoblamiento } \\
\text { Pesqueria desordenada } \\
\mathrm{T} / \mathrm{E}>70 \mathrm{~mm}, 4,5 \text { años }\end{array}$ & $\begin{array}{l}\text { Perlicultura en adultos }>140 \mathrm{~mm} \text { (talla legal) } \\
\text { Mabé Mrg } 18-20 \mathrm{~mm}: 36 \text { meses } \\
\text { Mabé Apx } 20-22 \mathrm{~mm}: 40 \text { meses }\end{array}$ \\
\hline $\begin{array}{l}\text { Haliotis laviegata } \\
180 \mathrm{~mm}\end{array}$ & $\begin{array}{l}\text { Australia, Tasmania } \\
\text { Dos o tres experiencias en total de corta duración, } \\
\text { demostrativas }\end{array}$ & $\begin{array}{l}\text { Laboratorio, cria en tierra y mar } \\
\text { Repoblamiento. Pesca turistica } \\
\mathrm{T} / \mathrm{E}>60 \mathrm{~mm}, 4 \text { años }\end{array}$ & $\begin{array}{l}\text { Perlicultura en adultos }>140 \mathrm{~mm} \text { (talla legal) } \\
\text { Mabé Mrg } 16-18 \mathrm{~mm}: 34 \text { meses } \\
\text { Mabé Apx } 18-20 \mathrm{~mm}: 38 \text { meses }\end{array}$ \\
\hline $\begin{array}{l}\text { Haliotis iris } \\
160 \mathrm{~mm}\end{array}$ & $\begin{array}{l}\text { Nueva Zelanda } \\
1 \text { granja comercial }\end{array}$ & $\begin{array}{l}\text { Laboratorio, cria en tierra y mar Repoblamiento. Pesca comercial } \\
\mathrm{T} / \mathrm{E}>60 \mathrm{~mm} \text { en } 2 \text { años }\end{array}$ & $\begin{array}{l}\text { Perlicultura en adultos }>120 \mathrm{~mm} \text { (talla legal) } \\
\text { Mabé Mrg } 14-16 \mathrm{~mm}: 34 \text { meses } \\
\text { Mabá Apx } 16-18 \mathrm{~mm}: 38 \text { meses }\end{array}$ \\
\hline $\begin{array}{l}\text { Haliotis discus hannai } \\
150 \mathrm{~mm}\end{array}$ & $\begin{array}{l}\text { Japón, China, Corea } \\
\text { Algunas experiencias, mercado demostrativo }\end{array}$ & $\begin{array}{l}\text { Laboratorio, cria en tierra y mar. Repoblamiento. Pesca comercial } \\
\mathrm{T} / \mathrm{E}>60 \mathrm{~mm}, 3 \text { años }\end{array}$ & $\begin{array}{l}\text { Perlicultura en ind. cultivados } \\
\text { Mabé Mrg } 10 \mathrm{~mm}: 24 \text { meses } \\
\text { Mabé Apx } 12 \mathrm{~mm}: 30 \text { meses }\end{array}$ \\
\hline $\begin{array}{l}\text { Haliotis kamtschatkana } \\
150 \mathrm{~mm}\end{array}$ & $\begin{array}{l}\text { British Columbia } \\
1 \text { granja demostrativa }\end{array}$ & $\begin{array}{l}\text { Laboratorio, cria en tierra. Repoblamiento } \\
\text { Veda permanente } \mathrm{T} / \mathrm{E}>60 \mathrm{~mm}, 4 \text { años. }\end{array}$ & $\begin{array}{l}\text { Perlicultura en adultos }>120 \mathrm{~mm} \text { (talla legal) } \\
\text { Mabé Mrg 14-16 mm: } 36 \text { meses } \\
\text { Mabé Mrg 16-18 mm: } 40 \text { meses }\end{array}$ \\
\hline $\begin{array}{l}\text { Haliotis asinina } \\
120 \mathrm{~mm}\end{array}$ & $\begin{array}{l}\text { Asia Sureste (Tailandia, Indonesia, Vietnam). } \\
\text { Unas cuantas granjas han hecho o hacen } \\
\text { perlicultura. Mercado demostrativo. }\end{array}$ & $\begin{array}{l}\text { Laboratorio, cría en tierra. Repoblamiento. } \\
\text { Pesca comercial } \mathrm{T} / \mathrm{E}>60 \mathrm{~mm}, 3,5 \text { años }\end{array}$ & $\begin{array}{l}\text { Perlicultura en adultos }>100 \mathrm{~mm} \text { (talla legal) } \\
\text { Mabé Mrg 12-14 mm: } 30 \text { meses. } \\
\text { Mabé Apx } 14-16 \mathrm{~mm}: 34 \text { meses }\end{array}$ \\
\hline $\begin{array}{l}\text { Haliotis tuberculata var.norte } \\
100 \mathrm{~mm}\end{array}$ & Bretaña, Galicia. Experimental no comercial. & $\begin{array}{l}\text { Laboratorio, cria en tierra y mar Repoblamiento } \\
\text { Veda permanente } T / E>60 \mathrm{~mm}, 3 \text { años }\end{array}$ & $\begin{array}{l}\text { Perlicultura en ind. cultivados } \\
\text { Mabé Mrg } 10 \mathrm{~mm}: 24 \text { meses } \\
\text { Mabé Apx } 12 \mathrm{~mm}: 30 \text { meses }\end{array}$ \\
\hline
\end{tabular}

'Hay una relación entre la talla/edad del organismo y el tamaño máximo de medio-núcleo y de núcleo esférico que el individuo puede recibir. Se asume que el tamaño mínimo comercial de una perla Mabé es de 13 mm de diámetro Mabé Mrg: implante en el margen externo de la concha (abulón); Mabe Apx: implante en el ápex de la concha (abulón) Mabe Mrg: implante en el margen externo de la concha (abulón); Mabe Apx: implante en el apex de la concha (abulón)
${ }^{3}$ Aunque un espesor de nácar de aprox. $0,8 \mathrm{~mm}$ por lo general se considera aceptable, en el tiempo de formación para todos los tipos de perla se asume un espesor minimo de nácar de $1 \mathrm{~mm}$. Cabe señalar que en el caso de las Icon-perlas,
el tiempo de formación es mucho menor (de 3 a 6 meses), para que no se pierdan los relieves 
Seaman y Martin Coeroli en Polinesia Francesa, y Quasim Alagarswami, Sri Dharmaraj, A.C. Victor, Daniel Dev y otros en la región de Tuticorin, Tamilnadu, India, donde se logró el desarrollo propio del cultivo de ciclo completo en laboratorio de la madreperla Lingha, Pinctada fucata, así como la perlicultura con instrumentos y núcleos fabricados localmente. En este punto es importante resaltar la gran labor del grupo científico de Tuticorin hacia el entrenamiento de mujeres y la difusión de conocimiento a través de la impartición de cursos abiertos para entrenamiento en técnicas de cultivo y perlicultura. No obstante, la competitividad de P. fucata en el mercado perlero de las especies chicas es numéricamente baja en comparación a Japón y China.

El desarrollo científico y tecnológico que continuaron otros investigadores, hacia finales del siglo XX había permitido la instalación de cerca de 1,500 granjas ostras perleras de talla grande en modalidad de cultivo extensivo produciendo 40 ton de perla libre de lujo anualmente (diámetro mayor de $10 \mathrm{~mm}$, genéricamente conocidas como Golden o Silver South Seas en Pinctada maxima y Black Pearls en $P$. margaritifera) (Hisada \& Fukuhara 1999, Muller 2005, 2009; Ponia 2006, Shor 2007, Taylor \& Strack 2008, Tisdell \& Poirine 2008) (Tabla 1). Adicionalmente, en el sur de Japón se concentran más de 3,500 granjas de $P$. martensii, la mayoría en la misma modalidad anualmente producen cerca de 50 ton de perlas más pequeñas y de menor precio, conocidas como Akoya (diámetro menor de $10 \mathrm{~mm}$, lo más común entre 6 y $8 \mathrm{~mm}$ ) (Japan Atlas 20124). Por su parte, China ha logrado desarrollar masivamente el cultivo de ciclo completo de $P$. chemnitzi combinando semilla de laboratorio y cultivo en campo, con lo cual en los últimos años ha introducido al mercado más de 20 ton de perlas 'Akoya' a bajo precio que compiten en calidad con las originales japonesas. Esto ya está dejando ver su efecto en el mercado mundial de perlas y en las perspectivas de las granjas perleras, en todos los canales de talla en las especies (Muller 2005, 2009; Ponia 2006, Fiske \& Shepherd 2007b, Shor 2007, Tisdell \& Poirine 2008, Monteforte \& Cariño 2012).

Retomando la experiencia de Fusia, China comenzó a producir 'perlas de arroz' masivamente a partir de los 1960s con sus 2 especies tradicionales, $H$. cumingii y $C$. plicata. Japón continúa produciendo las perlas Biwa originales a pequeña escala; en los 1970s introdujeron la hibridación de la casi extinta especie del lago Biwa, $H$. schlegelii, y su pariente china, $H$. cumingii, cosa que al mismo tiempo copiaron los chinos en sentido contrario. China aporta el 95\% (1,500 ton anuales o más) al mercado mundial de estas perlas (Dan \& Ruobo 2002, Fiske \& Shepherd 2007a, Zuhui \& Huaping 2010). El resto se compone de pequeños productores (con una docena de náyades nativas, la mayoría en modalidad de recolectaencierro) desperdigados en otros países asiáticos: India, Bangladesh, Filipinas, Vietnam, Tailandia, así como en el sureste de Estados Unidos. En términos del total del mercado perlero, las perlas de agua dulce cuentan por aproximadamente la mitad de la producción mundial de perlas (Fiske \& Shepherd 2007a, Taylor \& Strack 2008, Muller 2005, 2009). Cabe señalar que la cirugía de inducción a Biwa es diferente a la clásica de perla libre nucleada (ver comparativamente: Alagarswami \& Dharmaraj 1984, Pagcatipunam 1986, CMFRI 1991, Victor et al. 1995, Dan \& Ruobo 2002, Haws 2002, INDG 20125, Monteforte \& Bervera 2011). Desde hace algunos años se ha estado probando el uso perlas Biwa como núcleo (Bloom 2011). Paralelamente a la hibridación de $H$. cumingii $\mathrm{x} H$. schlegelii a escala industrial, la oferta de China al mercado perlero ya incluye bellas perlas esféricas multicolores que se venden en engarces por metro o por peso en bolsas, en amplia gama de tamaños y a precio de turista en los muchos barrios-bazares de ciudades como Shanghai, Xiyuan, Beijing, etc. Atractivas piezas de joyería con estas perlas son cada vez más frecuentes en los mercados populares de algunas ciudades europeas y americanas, donde gozan amplia aceptación por parte de la clientela.

Con respecto a las náyades en el mundo, la pesca intensiva sobre el valor de su concha nacarada también suministró durante siglos buena parte de la ávida demanda por las industrias de botonería e incrustación (Cocker 1919). Luego estos moluscos ganarían central importancia en la manufactura de los núcleos de prácticamente todas las perlas esféricas producidas en las granjas perleras marinas del mundo desde mediados del siglo XX a la fecha, cuando se empiezan a producir núcleos (y perlas tipo Biwa en menor escala) en la cuenca del Mississipi, Estados Unidos, en modalidad de recolecta y encierro de las grandes náyades Megalonaias nervosa, Quadrula quadrula y Fusconaria ebena. John Latendresse fundó

\footnotetext{
${ }^{4} J a p a n$ Atlas. 2012. Cultivated Pearls. Japan Atlas Nature. <http://web-jpn.org/atlas/nature/nature_fr.html>

5INDG. 2012. Freshwater pearl culture. India Development Gateway, Central Institute of Freshwater Aquaculture, Bhubaneshwar, Orissa. <http://www.indg.in/agriculture/fisheries/freshwater-pearl-culture>
} 
así la American Pearl Company, en la actualidad hay 6 o 7 granjas recolectoras que surten núcleos grandes -ya con dificultades- al canal de la perla libre de $10 \mathrm{~mm}$ de diámetro o mayor (P. maxima y P. margaritifera, y otras especies de tamaño grande como Pteria penguin, $P$. m. erythrensis, P. mazatlanica, Pteria sterna, así como abulones) ${ }^{6}$.

Con el desarrollo del cultivo de abulón en condiciones controladas a finales de los 1980s (Hahn 1988), en la mayoría de los países abuloneros se practica una combinación de pesca, cultivo y repoblamiento, bajo normas por lo general draconianas (Fisheries Victoria 2002, 2005; Prince 2004, 2005; Hutchins 2004, Mitchell \& Baba 2006, Rothaus et al. 2008, Strauss et al. 2009, Plagány \& Butterworth 2010, Cook \& Gordon 2010, FAO 2012). No obstante, la pesca mundial ha caído drásticamente de 20,000 ton en los 1970 s a menos de 10,000 ton en 2008. La declinación no se ha detenido, sumando zonas con veda permanente y especies amenazadas, mientras la pesca clandestina cobra una buena tajada en las poblaciones naturales, en ocasiones igual o superior a la pesca legal (Cook \& Gordon 2010, FAO 2012). Sin embargo, la producción en granja ha ido sustituyendo a la pesquería, registrando un acelerado crecimiento hasta más de 30,000 ton (Cook \& Gordon 2010, FAO 2012). Aproximadamente 15 especies de Haliotis se producen en condiciones de granja por algunos miles de productores dispersos en China, Taiwan, Japón, Corea, Tailandia, Australia, Tasmania, Sudáfrica, Nueva Zelanda, España, Francia, Canadá, Estados Unidos, México y Chile. China y Taiwan concentran respectivamente 300 y 400 granjas (Stevens 2003, Cook \& Gordon 2010). Se observan cultivos de ciclo completo continental (unidades de producción de semilla y alimento, con tinas y cisternas cubiertas o descubiertas y diferentes sistemas cerrados o semi-abiertos), y otros donde se combinan artes de cultivo en campo de diseño especial para el caso del abulón por su perfil vágil y necesidad de proveer alimentación a mano de algas frescas. En el mercado predomina la talla medallón o 'babyabalone' (especies chicas y/o animales jóvenes cultivados) y por lo general se presenta enlatado, mientras que la pesquería de individuos de mayor talla/edad aun provee producto gourmet de alto precio. Algunos productores han explorado la perlicultura con Mabé únicamente (Tabla 1), intimidados por la supuesta hemofilia y el alto costo de prueba/error en una curva de aprendizaje quirúrgico individual, de alto riesgo (Monteforte \& Bervera 2011). Llama la atención el trabajo pionero de La Place Bostwick en California (Boone 1935, Orcutt 1939) con los primero ensayos positivos de cirugía de perla libre nucleada en $H$. fulgens y/o $H$. rufescens. En la actualidad, menos de una docena de granjas con 3 o 4 especies (Tabla 1) producen entre 200 mil y 300 mil piezas de Mabé anualmente (Hutchins 2004). La perla libre aun no se ha logrado a nivel comercial en Haliotis, aunque no hay razones para suponer que los animales 'se desangran hasta morir' si se les hiere o lastima, sino más bien que la mortalidad se debe a niveles de tolerancia a diferentes grados de traumas, por ejemplo el uso de fierros en la pesca para desprender a los abulones del fondo (Gibson et al. 2002). Armstrong et al. (1971) y Aquilina \& Roberts (2000) demostraron que anestésicos adecuados y pequeñas heridas controladas no afectan la supervivencia, respectivamente en $H$. cracherodii y $H$. iris. Los resultados exitosos obtenidos en experimentos haciendo cirugía de perla libre nucleada en $H$. rufescens adicionan más dudas acerca de esta idea, toda vez que desde el punto de vista médico-veterinario y técnico, este procedimiento es factible (Monteforte \& Bervera 2011).

El avance tecnológico de cultivo en laboratorio y campo incluye otras especies marinas atractivas para la perlicultura, por ejemplo, el abulón europeo $H$. tuberculata (SUDEVAB 20107) y el caracol reina, Strombus gigas (Corral \& Ogawa 1987, Ogawa \& Corral 1987, Navarrete 2001, Davis 2003). También se conocen experimentos positivos en la producción de Mabé y Iconpearls con Astrea undosa, A. gibosa y Trochus niloticus (Paul Cross, GEO of Island Pearls, LCC, observ. pers.). Igualmente, se está explorando el potencial en otros

\footnotetext{
${ }^{6}$ Las náyades perleras (Unionidae), por su complicada bioecología y su ciclo reproductivo glochidiano son extremadamente vulnerables, escasas y amenazadas en todo el mundo debido a impactos acumulados en cuerpos de agua interiores, los cuales tienen mayor historial, diversidad e intensidad que en área marina: vertederos (agrícolas, industriales, urbanos), presas, urbanización/deforestación, mal uso de agua, introducción de especies foráneas y/o GMO depredadoras, competidoras y/o vectores indirectos, etc. La sobrepesca igualmente ha sido muy significativa en este historial. La invasión del mejillón zebra, Dreissena polymorpha, en el sureste de Estados Unidos es uno de los eventos más conocidos, y hay en Latinoamérica, Asia y Europa, centenares de 'focos rojos' en torno al deterioro ambiental generalizado de ríos y lagos debido al uso excesivo de recursos y ocupación de espacios con alto grado de huella ecológica. El efecto negativo sobre especies nativas valiosas de aguas interiores evidentemente no se restringe a las náyades perleras y sus peces huésped.

${ }^{7}$ SUDEVAB 2010. Sustainable abalone aquaculture. Symposium of Projects, 20 Oct. 2010. Sustainable Development of European SMEs Engaged in Abalone Aquaculture, Aber Wrac'h, Bretagne, France. < http://www.sudevab.eu/partners.php>
} 
grandes bivalvos marinos con nácar coloreado como Nodipecten subnudosus (Wight 2008).

\section{EsTADO DE AVANCE TÉCNICO DE LA PERLICULTURA}

La perlicultura se aplica actualmente con diferente escala comercial, mediante adaptaciones diversas de implantación (Mabé, Icon-pearl) y/o cirugía (perla libre con o sin núcleo) en alrededor de 12 especies de moluscos marinos (7-8 ostras perleras, 4-5 abulones, y el caracol reina del Caribe) (Tabla 1), y 4 o 5 náyades perleras. La tecnología y manipulaciones de inducción han evolucionado hacia prácticas más sofisticadas: aplicación de terapias con drogas y anestésicos para relajar al animal y herramientas modernas para trepanar o cortar la concha, así como productos adhesivos para sujetar a la concha en cualquier medio, e.g., 3/4 de núcleo o figura-icono fabricadas en plástico, resina, cerámica, acero inoxidable, etc. (Fankboner 1993, Monteforte et al. 1998, 2004; AcostaSalmón et al. 2005, Haws et al. 2006, Ruiz-Rubio et al. 2006, Acosta-Salmón \& Davis 2007, 2010; Monteforte \& Bervera 2011). Para la cirugía perlera hay suministro de los instrumentos quirúrgicos especiales (base de operación, copas nucleadoras, porta-injerto, bisturís circulares, retractor-guía, etc.) y núcleos en Estados Unidos, Australia, Polinesia Francesa, India, Tailandia, Japón, China. Con maquinaria y material adecuados los instrumentos se podrían fabricar localmente, como en India desde los 1970s. Los procedimientos de cirugía son de dominio público en una gran diversidad de fuentes documentales (Pagcatipunan 1986, Alagarswami \& Dharmaraj 1984, CMFRI 1991, Victor et al. 1995, Dan \& Ruobo 2002, Haws 2002, INDG 20124, Monteforte \& Bervera 2011), incluyendo la colección completa del Bulletin of the National Pearl Research Laboratory en varias bibliotecas del mundo (e.g., Univ. British Columbia en Vancouver, Canadá; UCSD-SIO en San Diego, California; MNHN en Paris, Francia).

Es pertinente considerar aquí las 65 patentes de Mikimoto para el cultivo y la perlicultura en P. martensii, que se describen por Cahn (1949). Si bien los sistemas de cría (en campo, y especialmente en laboratorio), son más proclives a innovaciones patentables -lo cual se puede comprobar en internet- no obstante muchos investigadores han logrado patentar diferentes adaptaciones de la milenaria técnica china de implante principalmente en abulones (K. Uno en 1957, H. Gotho en
1975, P. Fankboner en 1993) (Monteforte \& Bervera 2011). Por su parte, la cirugía de las diferentes perlas libres no ha sido objeto de variantes sustancialmente diferentes de las registradas por Mikimoto o el procedimiento de Fusia, excepto un procedimiento mecánico para acceder al cuerpo de Strombus gigas perforando la concha (Acosta-Salmón \& Davis 2010).

Fuera de China las granjas de náyades perleras no se han desarrollado plenamente por lo difícil y costoso que resulta el perfeccionamiento tecnológico efectivo, aunque en los últimos años se han logrado importantes adelantos en la propagación de peces artificialmente infestados con gloquidias 'ordeñadas' de hembras grávidas adultas y en la cría de ciclo completo en sistemas cerrados (Neves 2004, Barnhart 2006, Kovitvadhi et al. 2008, 2009; Degerman et al. 2009, Thomas et al. 2010). Para la perlicultura, las especies de náyades deben cumplir con ciertos requisitos: ser grande y con manto grueso, nácar atractivo, disponibilidad, tecnología, etc., sin descartar la sanidad y grado de manejo de los cuerpos de agua. Cada receptor puede recibir hasta 25 o más de injertos en total por sesión; los granos de nácar se recuperan mediante el mismo procedimiento (generalmente en 2-2,5 años). Gracias a su longevidad, los animales pueden recibir nuevos tratamientos varias veces en su vida, se dice que hasta 50 en los híbridos chinos. Por su bajo precio y oferta, las 'perlas de arroz' empiezan a emplearse como núcleo de perla libre marina en $P$. chemnitzi, así como para uso en los mismos mejillones perleros (Fiske \& Shepherd 2007 a, b, Bloom 2011). Perlas nucleadas esféricas y sub-esféricas de la náyade híbrida china ya se observan en abundancia en el mercado compitiendo ventajosamente con las perlas marinas tradicionales por su amplio rango de tamaños, variedad de colores (teñidos), precios económicos e indudable atractivo ornamental.

Ante la escasez de núcleos esféricos grandes, resultado de los impactos en las áreas propicias a las grandes náyades perleras y sus peces huésped, principalmente en Estados Unidos (Lindenmayer et al. 2009, Thomas et al. 2010), desde hace algunos años se han explorado alternativas en la concha de otros moluscos con excelentes resultados (Tridacna spp. y algunos caracoles Trochidae y Strombidae), así como en la bironita (Ventouras 1999), y en la aplicación de técnicas de encapsulado metálico al vapor en núcleos dañados o de

${ }^{8}$ Monteforte M \& H Bervera. 2011. State of the art, innovations and perspectives of pearl culture in Haliotis spp. (Gastropoda: Haliotidae). 44th Joint Meeting of the Western Society of malacologists. La Paz, BCS, Mexico, June 12-17, 2011. p.27. 
baja calidad (Paul Cross, CEO, American Bio-Gem). Además, la perlicultura in vitro empieza a considerarse como innovación técnica factible (Dharmaraj \& Suja 2010). Mientras tanto, perlas libres de $S$. gigas han empezado a aparecer en el mercado (Rose Pearl, LCC., desde 2010) y las Icon-pearls están creando un canal atractivo (Island Pearls, American Bio-Gem, desde 2010).

\section{AsPeCtos técnicos, costos, CURVAS de APRENDIZAJE}

El principal reto para crear una granja perlera no radica exclusivamente en la producción de perlas, sino en asegurar un suministro constante de animales cultivados viables y sacrificables con los que se pueda practicar y aprender las técnicas de perlicultura (Monteforte 2013). Esto implica alcanzar una validación técnica-operativa bien definida en el manejo de la granja y sus ciclos de producción (e.g., indicadores de eficiencia al menos en la media, en condiciones reales). Para esto, se necesita dedicación y paciencia para desarrollar las curvas de un aprendizaje cuya complejidad, costo y duración varían en función de un sinnúmero de factores: especie y diferentes necesidades de infraestructura y equipo en campo o laboratorio y sus servicios de soporte (producción de alimento, sistemas de agua, etc.), instalaciones cubiertas o descubiertas de cría en tierra (estanquería, tinas, embalses, etc.), tipo de artes de cultivo en campo en su caso; eficiencia de la tecnología disponible (viabilidad de semilla/juvenil de laboratorio, dominio de manejo en campo, etc.); tipo de sitio y condiciones logísticas (geomorfología, hidro-oceanografía, distancias, tipo de embarcaciones, acceso, comunicación, servicios, etc.), nivel de apropiación de los usuarios (diferente si son empresas o comunidades de pescadores), así como permisos, licencias o concesiones, y eventuales pagos de asesoría, consultoría y/o entrenamientos y transferencias tecnológicas. Por lo demás, los resultados difícilmente son predecibles incluso a corto plazo, en particular bajo las condiciones globales imperantes donde el comercio de ornamentos de lujo y productos gourmet tiene lugar en otra suerte de prioridades.

La puesta en obra y el entrenamiento de ciclo completo se ajusta a ritmos de tiempo y grados de complejidad diferente. El primer aspecto a tomar en cuenta es el aseguramiento de una fuente constante y suficiente de animales adultos aptos para la perlicultura, de preferencia sin incidir en la recolecta sobre las poblaciones naturales. La técnica de implantación (Mabé, Icon-pearl) es sencilla, no intrusiva, y mediante manipulaciones adecuadas los animales pueden ser re-implantados después de una cosecha. Sin embargo, el entrenamiento de cirugía para perla libre implica ensayos de prueba/error con sacrificio. Al parecer las perlas Biwa se consiguen con pocos ensayos (Pagcatipunam 1986, INDG 20124); para la perla nucleada en las ostras perleras varían entre 3,000 en las especies chicas a 10,000 en grandes y gigantes (com. pers. durante el Congreso Internacional Pearls'94, Hawaii: Dra. Daisy Ladra, Dr. Phillipe Cabral y Dan Emery; Victor et al. 1995, Haws 2002). Expertos en Pt. sterna ocuparon alrededor de 7,000 ensayos (Nava et al. 2000), y en Pt. penguin aún no se conocen noticias de resultados en este aspecto. En abulón y otros gastrópodos podrían ser números menores (Monteforte \& Bervera 2011).

Aunque la presencia de un maestro entrenador puede influir en la curva de aprendizaje, cada aprendiz debe alcanzar y demostrar superación respecto a una marca en la tasa de éxito de perlas con características de tamaño y calidad pre-establecidas en los exigentes estándares del mercado perlero (Tabla 1). La rentabilidad mínima aceptable, con un valor virtual por perla contra el balance financiero de un proyecto perlero, oscilaría entre 33 y $36 \%$ de perlas de calidad comercial que se deben obtener en un tiempo y número de ensayos razonables, según la especie, la capacidad de la granja en suministrar lotes de animales sacrificables y el número de aprendices simultáneos (panorama de selección). La probabilidad de perfeccionamiento a nivel personal raramente es predecible y no hay garantía de éxito. Si existiese alto suministro de animales procedentes de laboratorio con talla/edad adecuada para la perlicultura, esto ayudaría en el factor tiempo y disponibilidad de animales sacrificables para ensayos, y en el menor costo acumulado de la curva de aprendizaje. En teoría, el dominio de la producción en ciclo completo y de la perlicultura en los moluscos perleros abre escenarios de negocio en otro tipo de entramado, aunque esta opción presenta algunas desventajas que se describirán más adelante.

Considerando que existen diferencias anatómicas relacionadas con la implantación y/o la cirugía entre las especies, la curva de aprendizaje presenta otras características además de la aptitud personal. Un técnico perlicultor en una especie, necesariamente debe adaptarse a otra nueva, modificando la forma y tamaño de los instrumentos y las manipulaciones. Esto ocupa tiempo y animales sacrificables, y tampoco hay garantía inmediata. En el caso de granjas perleras con abulón, caracol reina, náyades y otras que ocupen producción de semilla o cría en condiciones de laboratorio (e.g., estanquería, sistemas cerrados, etc.), las perspectivas de incidir en el mercado 
perlero implican dominar tecnología más complicada y mayor costo de producción, con lo cual se elevan riesgo $\mathrm{y}$ valor de las curvas de aprendizaje en general.

\section{Condiciones DE PLANIFICACIÓN PARA UNA GRANJA PERLERA}

Aunque la información es abundante, cada granja posee sus propias estrategias de manejo (algunas más complejas y costosas que otras), las cuales a su vez dependen de los insumos y conocimientos disponibles en una región dada. Es evidente que el discriminante primario en la planificación financiera de una granja perlera radica en el origen de la semilla (captación por colectores o producción controlada en laboratorio), y en la modalidad de cría (en tierra, tipo de sistema y/o artes de cultivo, duración y carga de trabajo en el ciclo). Las unidades de producción de alimento (microalgas, probióticos y otras dietas) o la alimentación a mano (abulones y otros gastrópodos perleros) representan una importante sección de los aspectos financieros. El manejo de los ciclos de producción ocupa mano de obra intensiva y bien entrenada en todos los casos.

En el cultivo extensivo existe dependencia a ciclos de reclutamiento natural que son poco predecibles y no se pueden controlar; la ventaja es que la semilla o juveniles capturados en el medio muestran mejor desempeño general que las generaciones de laboratorio, especialmente en las ostras perleras grandes cuya industria se apoya casi por completo en la captación de semilla (Monteforte 2013). La recolecta de adultos silvestres para practicar perlicultura no es recomendable, considerando que se aplica en recursos escasos y vulnerables ${ }^{9}$. Es un hecho, que son hipersensibles a las manipulaciones y son poco resistentes a una intervención agresiva como la cirugía. Por su parte, el suministro de alta abundancia de semilla por técnicas de laboratorio y la aptitud o viabilidad de estas generaciones para incorporarse al crecimiento comercial de una granja, depende del perfeccionamiento de tecnología costosa que demanda alta especialización, y cuya sensibilidad a riesgos se maneja con umbrales de tolerancia muy estrechos: la mortalidad acumulada es alta y por lo general se manifiesta temprano, esto define principalmente la relación entre el tamaño de producción, la capacidad de recepción inicial y los clareos posteriores en las artes de cultivo, esto 2 últimos factores son densodependientes (de hecho esta condición es válida para toda especie sometida a manejo acuícola comercial). En el caso de las ostras perleras grandes, la aportación de efectivos de laboratorio al mercado perlero es mínima, a escala experimental y en proceso de estudio. Más que a la perlicultura, los supervivientes se destinan al repoblamiento, aunque esta práctica también se encuentra sujeta a controversias en torno a su efecto en la diversidad genética y sanidad en las granjas, en particular en las lagunas cerradas de los atolones en el Pacífico (Arnaud-Haond et al. 2003)

El principal problema de las generaciones de laboratorio subsiste en la mortalidad masiva desde las etapas tempranas de cría, y es común que los sobrevivientes presenten deficiencias que no favorecen la aptitud para la perlicultura (Rose \& Baker 1994, Doroudi et al. 1999a, b; Doroudi \& Southgate 2000, Pit \& Southgate 2000, Taylor et al. 2004, Yu \& Chu 2006, Kvingedal et al. 2008, Linard 2011, Yuewen et al. 2011). Síntomas que se pueden observar: concha delgada y frágil, ornamentos superficiales y marginales defectuosos o ausentes, talla/ edad menor y aspecto débil general con respecto a adultos originarios de semilla colectada (e.g., saco gonadal subdesarrollado, nácar opaco y sin oriente, poca resistencia a anestesia y manipulaciones, etc.). Evidentemente además, siendo descendientes de unos cuantos reproductores, hay monotonía en la diversidad de color del nácar -color de fondo o dominante, y tonos primarios y secundarios).

En el abulón al parecer no hay diferencias notables en cuanto las características del nácar de generaciones cultivadas en laboratorio y los animales naturales (Gray \& Smith 2004, Auzoux-Bordenave et al. 2010), pero no se ha comprobado efectivamente en las perlas. Resulta interesante notar que la perlicultura (Mabé) en abulón se aplica mayormente en adultos de pesquería de talla/edad al menos igual a la reglamentaria (Tabla 1). La perlicultura de Mabé y perla libre en estos moluscos se ha visto retrasada por razones más de índole económico y administrativo que por dificultades técnicas o médicoveterinarias relacionadas con una supuesta hemofilia o intolerancia funcional de los animales hacia este tipo de cirugía (Hutchins 2004, Monteforte \& Bervera 2010a, b, 2011).

Las consideraciones anteriores implican que la evaluación de un modelo realista con potencial rentable

${ }^{9}$ En Australia (zona de Broome), la perlicultura se lleva mediante recolecta-encierro de $P$. maxima bajo un estricto sistema de zonificación y cuotas. No es de extrañar que los empresarios guarden celosamente la 'propiedad' sobre sus técnicos perlicultores. 
en torno a granjas perleras puede variar significativamente según la fuente de materia prima (producción en laboratorio, cultivo extensivo, recolecta, o combinación de éstas), y en los factores numerales obligatorios de un proyecto tecnológico y/o plan comercial, cualquiera que sea su perfil de puesta en obra o sus proyecciones a futuro. Al final de la línea, la factibilidad integral se mide poniendo en balanza el costo acumulado, y el número y valor virtual de las perlas obtenidas, eventualmente adicionando los costos de venta y mercadotecnia (e.g., diseños y fabricación de joyería). De tal manera, la recuperación efectiva de la inversión y la generación de ganancias pudieran no ser tan satisfactorias o rápidas como lo previsto en el escritorio.

\section{Discusión}

La oferta tecnológica de una granja perlera moderna en principio debiera asegurar por lo menos el dominio completo de todas las etapas de producción, incluyendo el suministro de semilla viable y la curva de aprendizaje (tanto del cultivo en campo como de la perlicultura), así como las estrategias adecuadas para la mercadotecnia y comercialización del producto. Una estimación realista del tiempo en que una granja perlera alcanza rentabilidad oscilaría entre 4 y 10 años, según la especie y las condiciones en que se desarrollaría un determinado proyecto productivo. En tal contexto, la tecnología de laboratorio es un desarrollo independiente per se, el cual una vez definido coadyuvaría al suministro de animales sacrificables para el entrenamiento simultáneo de varios técnicos perlicultores, y más a tarde al aseguramiento económico-operativo de planes de negocio de diferente escala. Hipotéticamente, considerando las implicaciones globales, el perfeccionamiento de esta tecnología, aun muy incompleta en casi todos los moluscos perleros, proveería enorme potencial de crecimiento.

A pesar de los obstáculos, el atractivo económico de la industria perlera continúa siendo una motivación por parte de diversos emprendedores acuícolas en muchas regiones del mundo que poseen especies valiosas y oportunidades para poner en obra granjas perleras en el mar o en cuerpos de agua continentales. No han cesado de aumentar los estudios aplicados al desarrollo tecnológico del cultivo apuntando a la producción de perlas, tanto en las especies tradicionales como en otras nuevas, aún a costa de introducir especies foráneas como en Chile con los abulones $H$. rufescens y $H$. discus hannai (Flores-Aguilar et al. 2007).
En todos los casos los proyectos tecnológicos se diseñarían en diversos escenarios de operación e inversión a partir de cantidad de parámetros de manejo y de sus respectivos límites de sensibilidad- que deben estar plenamente identificados en todas y cada una de las variables en juego, considerando además que la manufactura, instalación y manejo de las granjas en condiciones reales, sea de laboratorio o campo, demanda carga intensiva en mano de obra con entrenamiento especializado (Monteforte 2013). El estudio de los ejemplos de éxito juega un papel importante en la planeación de una nueva iniciativa, pero la adaptación y validación son requisitos indispensables y diferentes en cada experiencia. En el caso concreto de las especies que ocupan tecnología de laboratorio, en la mayoría hay mucho camino por recorrer para llegar al estado de dominio demostrable, toda vez que el costo de montar un laboratorio eficiente (con técnicos especializados, sistemas de soporte, etc.), podría ser inalcanzable para un productor que deberá pagar caro por una adaptación tecnológica propia, o aceptar asociaciones poco ventajosas y sin garantía de éxito por servicios de transferencia y entrenamiento, derechos de patente y contratos por lo general abusivos.

En el siglo XXI se cuenta con el conocimiento científico y tecnológico más avanzado disponible actualmente, y con la perspectiva de que el crecimiento y diversificación de las granjas perleras es técnicamente factible, concediendo potencial competitivo a las regiones donde existen o se pueden aplicar tecnologías en sus especies nativas. Pero se enfrentarán a un mercado elitista con altos estándares de tamaño y calidad, donde el nácar y las perlas han pasado a ser simples ornamentos de producción comercial, por lo que es de esperar que en los próximos años las granjas perleras se vean envueltas a nivel global en una dinámica difícilmente predecible. Las lecciones a aprender y las tendencias en el mercado perlero moderno, sugieren a los productores reales y potenciales considerar alternativas, en primer lugar en función de tecnologías disponibles, sus tiempos y costos de adaptación, perfeccionamiento y/o grado de dominio; en segundo lugar, la diversificación al policultivo y los esquemas de maricultura turística integral (Monteforte \& Cariño 2011) parecen ser una derivación lógica ante las crisis globales y los vaivenes de calidad, oferta y demanda, en especial en el mercado de nácar y perlas. El repoblamiento, conservación y buenas prácticas de cultivo, y el mantenimiento de alta calidad en los productos, representan lineamientos de retroalimentación a la rentabilidad de las propias granjas. 


\section{Conclusiones}

Sin duda el simbolismo del nácar y las perlas ha sido y continúa siendo un impulso primario en el desarrollo socioeconómico de muchas regiones del mundo que poseen ventajas y oportunidades en este aspecto. El aprovechamiento sustentable beneficiaría de diferentes maneras a comunidades costeras y empresarios. Al desarrollar ciencia aplicada útil para el cultivo de ciclo completo, el bono de valor agregado con perlicultura y joyería podría apuntalar la conversión productiva de la pesquería a la maricultura integral y proveer soluciones a problemas que son comunes en estas regiones, como la sobrepesca, declinación de las poblaciones, e impactos acumulados en la vulnerabilidad de las comunidades de pescadores ribereños (Alcalá 2011, Monteforte \& Cariño 2011). La definición de proyectos tecnológicos de cultivo y perlicultura, podría actuar como una fórmula de crédito bancario a largo plazo en los planes financieros, considerando que el suministro de efectivos y la curva de aprendizaje completa concentran gran parte de la sensibilidad en los modelos de negocio, donde los factores de riesgo son abundantes y variados, y los criterios de mínimos aceptables son intransigentes.

Una granja acuícola comercial establecida -de cualquier especie- generalmente comenzó a escala demostrativa, validando a pasos los ciclos de producción y la perlicultura. Sin duda los esquemas son extremadamente variables en cuanto al tamaño de la inversión y los resultados esperados, no obstante, calculando modelos coherentes, los indicadores financieros clásicos (TIR, VAN, C/B, Proformas, etc.) son positivos incluso en escenarios de eficiencia media. De hecho, en la planeación virtual de los valores agregados, el límite de una granja perlera radicaría en la capacidad de concebir utopías, aunque la entrada, permanencia, crecimiento y diversificación en el mercado perlero moderno está encontrando dilemas en los nuevos conceptos de sustentabilidad y adaptación, aunado a una creciente oferta, saturación de la actividad y del mercado, y diversas influencias incluso de contexto global en fluctuaciones climáticas, desequilibrio en las economías y crisis de valor en las sociedades, cultura e identidad. Es evidente que en América Latina y en otros países aun existen localidades propicias en costas y cuerpos de agua interiores donde no se ha aprovechado cabalmente la riqueza perlera con las oportunidades disponibles, adelantos de conocimiento y valor de las especies nativas. Sin embargo, un análisis sumario de los razonamientos examinados en este trabajo finalmente parece sugerir que los modelos tradicionales verticales ya establecidos y/o las iniciativas de nuevo ingreso contienen variables directas y colaterales impredecibles, donde la línea divisoria entre la especulación y la realidad a veces no se distingue. El estancamiento en la generación de ciencia útil para desarrollo e innovación de tecnologías productivas, la marginación de comunidades vulnerables a favor de intereses empresariales, y la auto-promoción de tecnólogos vendiendo grandes negocios, son síntomas que resaltan en este contexto. Iniciar una granja perlera es en este momento un objetivo totalmente factible para un grupo de profesionales afines a la materia, o en todo caso un empresario privado puede manejar su capital propio y crear empleos de responsabilidad mediante contratos y/o asociaciones bien equilibradas. En algunos países existen canales o programas nacionales accesibles para apertura de fondos destinados a fomentar el desarrollo regional y/o facilidades crediticias para la vinculación de capitales con proyectos tecnológicos generados por instituciones públicas como universidades o centros de investigación. Mediante la creación de sinergias más amplias, por ejemplo con entidades de gobierno, grupos civiles, comunidades, etc., se puede involucrar a organismos como FAO, BID, PNUD, entre otras, o bien fundaciones, las cuales por lo general pueden aliarse con las Organizaciones no Gubernamentales (ONGs) de la localidad.

Naturalmente, un proyecto perlero moderno se puede fundamentar sobre la seguridad técnica de que en cierto tiempo la primera generación criada producirá perlas comercializables. El tamaño de inicio y el esperado de crecimiento, imaginativamente no tiene límites más que en el tamaño de inversión que se logre inyectar y la inventiva de los promotores. No obstante, la adaptación de las tecnologías de cultivo en condiciones reales no es tarea fácil en estas fases donde ocurren la mayor parte de los fracasos, sin contar el efecto de externalidades que pueden variar desde situaciones de gobierno en los países hasta mortalidades masivas por enfermedades y derrames contaminantes, o aspectos relacionados o no con el cambio climático. De todas maneras, el concepto actual del 'mito perlero', sin haber perdido su raíz crematística, se aplica en un momento en que la tecnología de cría de los moluscos perleros ha adquirido un papel indispensable como intermediario para lograr acceder a los beneficios económicos en uno de los mercados más cuadrados y sensibles que existen actualmente en el área de la acuacultura y/o la venta de ornamentos. La recomendación 
más pertinente que podemos aportar sobre la base del presente trabajo y el historial de experiencia acumulada en la materia, es analizar con mucha cautela las fortalezas regionales disponibles, las alternativas a tomar, y las características distintivas de las regiones y sus especies nativas, en comparación a la situación actual de la industria y las perspectivas que brevemente hemos revisado en este documento.

\section{LITERATURA CITADA}

Acosta-Salmón H \& M Davis. 2007. Inducing relaxation in the queen conch Strombus gigas (L.) for cultured pearl production. Aquaculture 262: 73-77.

Acosta-Salmón H \& M Davis. 2010. Methods for producing cultured pearls in Conch and other gastropods. U.S. Patent Application Publication. <www.google.com/patents/ US20100251968>

Acosta-Salmón H, E Martínez-Fernández \& PC Southgate. 2005. Use of relaxants to obtain saibo tissue from the blacklip pearl oyster Pinctada margaritifera and the Akoya pearl oyster Pinctada fucata. Aquaculture 246: 167-172.

Alagarswami K \& S Dharmaraj. 1984. Manual on pearl culture techniques. Bulletin of the Central Marine Fisheries Research Institute, CMFRI, India, Special Publication: 1-42.

Alcalá G. 2011. Pescadores en América Latina y el Caribe. Espacio, población, producción y política. 1: 1-376; 2: 1415. Unidad Multidisciplinaria de Docencia e InvestigaciónSISAL, Facultad de Ciencias, UNAM, México.

Aquilina B \& R Roberts. 2000. A method for inducing muscle relaxation in the abalone, Haliotis iris. Aquaculture 190(34): 403-408.

Armstrong DA, JLArmstrong, SM Krassner \& GB Pauley. 1971. Experimental wound repair in the black abalone, Haliotis cracherodii. Journal of Invertebrate Pathology 17(2): 216-227.

Arnaud-Haond S, V Vonau, F Bonhomme, P Boudry, J Prou, T Seaman, M Veyret \& E Goyard. 2003. Spat collection of the pearl oyster (Pinctada margaritifera cumingii) in French Polynesia: an evaluation of the potential impact on genetic variability of wild and farmed populations after 20 years of commercial exploitation. Aquaculture 219(1-4): 181-192.

Auzoux-Bordenave S, A Badou, B Gaume, S Berland, MN Helléouet, C Milet \& S Huchette. 2010. Ultrastructure, chemistry and mineralogy of the growing shell of the European abalone Haliotis tuberculata. Journal of Structural Biology 171(3): 277-290.

Barnhart MC. 2006. Buckets of muckets: a compact system for rearing juvenile freshwater pearl mussels. Aquaculture 254: 227-233.

Bell KC. 2006. Natural pearl formation as seen through macrophotography. Proceedings of the Fourth International Gemological Symposium and GIA Gemological Research Conference. Gems \& Gemology 42(3): 169-170.
Bloom S. 2011. Across the Chinese freshwater pearl border: entering the transformation. Ornament 35(1): 56-61.

Boone A. 1935. Pearls made to order by surgical operations. Popular Science: 24-25.

Cahn A. 1949. Pearl culture in Japan. United States Department of the Interior, Fish and Wildlife Service, Fishery Leaflet 357: 1-91.

Cariño M. 1996. The cultured pearl polemic. Science and business went face to face when cultured pearls first entered the international market. Journal of World Aquaculture 27(1): 42-44.

Cariño M \& M Monteforte. 1999. El primer emporio perlero sustentable del mundo: La Compañía Criadora de Concha y Perla de la Baja California, S.A. y perspectivas para México, 325 pp. UABCS-CONACULTA-FONCA, México.

Cariño M \& M Monteforte. 2006. Histoirie mondiale de nacres et des perles: Pêche, culture et commerce, 260 pp. Editions L'Harmattan, Collection Maritimes, Paris.

Cariño M \& M Monteforte. 2009. An environmental history of nacres and pearls: fisheries, culture and commerce. Global Environment: A Journal of History and Natural and Social Sciences 3: 46-69.

CIBJO. 2010. The pearl book. Natural, cultured \& imitation pearls. -Terminology \& classification. Confédération Internationale de la Bijouterie, Joaillerie, Orfèvrerie, des Diamants, Perles et Pierres. CIBJO/GEM Materials, Pearl Commission 2007-6 :1-47.

CMFRI. 1991. Pearl oyster farming and pearl culture, 104 pp. Training Manual 8, Central Marine Fisheries Research Institute, Cochin, India. FAO Corporate Document Repository, Fisheries and Aquaculture Department, Roma. <http://www.fao.org/docrep/field/003/ab726e/ AB726E00.htm>

Cocker RE. 1919. Fresh-water mussels and mussel industries of the United States. Bulletin of the Bureau of Fisheries 36, 1917-1918: 1-90.

Cook PA \& HR Gordon. 2010. World abalone supply, markets, and pricing. Journal of Shellfish Research 29(3): 569-571.

Corral JL \& J Ogawa. 1987. Cultivo masivo de larva de caracol Strombus gigas en estanques de concreto. Proceedings of the Thirty-Eight Annual Gulf and Caribbean Fisheries Institute, Miami, pp. 35-352.

Dan H \& G Ruobo. 2002. Freshwater pearl culture and production in China. In: Aquaculture Asia 7: 1-58. Network Aquaculture Centers Asia-Pacific, Bangkok.

Davis M. 2003. Species profile: Queen conch, Strombus gigas. Southern Regional Aquaculture Center (SRAC) 7203: 1-12.

Degerman E, S Alexanderson, J Bergengren, L Henrikson, BE Johansson, BM Larsen \& H Söderberg. 2009. Restoration of freshwater pearl mussel streams, 64 pp. WWF Sweden, Solna. 
Dharmaraj S \& CP Suja. 2010. In vitro culture of mantle tissue of the abalone Haliotis varia Linnaeus. Tissue and Cell 37(1): 1-10.

Doroudi MS \& PC Southgate. 2000. The influence of algal ration and larval density on growth and survival of blacklip pearl oyster Pinctada margaritifera (L.) larvae. Aquaculture Research 31: 621-626.

Doroudi MS, PC Southgate \& RJ Mayer. 1999a. Growth and survival of black-lip pearl oyster larvae fed different densities of microalgae. Aquaculture International 7: 179187.

Doroudi MS, PC Southgate \& RJ Mayer. 1999b. The combined effects of temperature and salinity on embryos and larvae of the black-lip pearl oyster, Pinctada margaritifera (L.). Aquaculture Research 30: 271-277.

Fankboner PV. 1993. Pearls and abalones. World Aquaculture Magazine 19(6): 28-38.

FAO. 2012. State of world fisheries and aquaculture 2012. FAO Fisheries and Aquaculture Department, FAO, Rome. < http://www.fao.org/docrep/016/i2727e/i2727e.pdf>

Fassler RC. 1994. Abstracts of papers presented at Pearls '94 International Pearl Conference, Honolulu, Hawaii, May 1419, 1994. Journal of Shellfish Research 13: 325-354.

Fisheries Victoria. 2002. Victorian abalone fishery management plan, 66 pp. The State of Victoria, Department of Natural Resources and Environment, Melbourne. <http:/ /www.vada.com.au/Documents/IndustryInfo/CZDocs/ AbaloneFMP.pdf>

Fisheries Victoria. 2005. Fisheries (Abalone) bill of 2005, 241 pp. Fisheries Victoria, Melbourne.

Fiske D \& J Shepherd. 2007a. Continuity and change in Chinese freshwater pearl culture. Gems \& Gemmology 43(2): 138-145.

Fiske D \& J Shepherd. 2007b. Chinese Akoya cultured pearls. Gems \& Gemmology 43(2): 171-172.

Flores-Aguilar R, A Gutiérrez, A Ellwanger \& R SearcyBernal. 2007. Development and current status of abalone aquaculture in Chile. Journal of Shellfish Research 26(3): 705-711.

George D. 2008. Debunking a widely held Japanese myth. Historical aspects on the early discovery of the pearl cultivating technique, $10 \mathrm{pp}$. Pearl World, The International Pearling Journal. <http://www.pearl-guide.com/J-FM\%202008.pdf >

Gervis MH. 1991. A bibliography of the pearl oysters (Bivalvia: Pteriidae), 99 pp. Overseas Development Administration of the United Kingdom, London / Manila.

Gibson PT, DG Worthington, C Blount \& NLAndrew. 2002. Incidental damage of blacklip abalone (Haliotis rubra) by commercial divers in New South Wales, Australia. Journal of Shellfish Research 21(2): 787-792.
Gray EB \& AM Smith. 2004. Mineralogical variation in shells of the blackfoot abalone, Haliotis iris (Mollusca: Gastropoda: Haliotidae), in Southern New Zealand. Pacific Science 58(1): 47-64.

Hahn KO. 1988. Handbook of culture of abalone and other marine gastropods, 348 pp. CRC Press, Boca Raton.

Haws M. 2002. The basic methods of pearl farming: A Layman's manual. University of Hawaii. Center for Tropical and Subtropical Aquaculture Publication 127: 1-74. <http:// w w w. c t s a . org / f i l e s / p u b lic a t i on s / CTSA_1276316728619239483681.pdf>

Haws M, SC Ellis \& EP Ellis. 2006. Producing half-pearls (Mabe), 116 pp. Coastal Resources Center, University of Rhode Island, Narragansett. <http://pdf.usaid.gov/ pdf_docs/PNADK668.pdf>

Hisada Y \& T Fukuhara. 1999. Pearl marketing trends with emphasis on black-pearl market. FAO Field Document 13, FAO Fisheries and Aquaculture Department, FAO, Rome. <http://www.fao.org/docrep/005/AC890E/AC890E00.htm >

Hutchins P. 2004. Culturing abalone half-pearls: The story of the New Zealand Eyris Blue Pearl ${ }^{\mathrm{TM}}$. The Australian Gemmologist 22(1): 10-20.

Kovitvadhi S, U Kovitvadhi, P Sawangwong \& J Machado. 2008. A laboratory-scale recirculating aquaculture system for juveniles of freshwater pearl mussel Hyriopsis (Limnoscapha) myersiana (Lea, 1856). Aquaculture 265: 169-177.

Kovitvadhi S, U Kovitvadhi, P Sawangwong, $P$ Trisaranuwatana \& J Machado. 2009. Morphometric relationship of weight and size of cultured freshwater pearl mussel, Hyriopsis (Limnoscapha) myersiana, under laboratory conditions and earthen pond phases. Aquaculture International 17: 57-67.

Kvingedal R, BS Evans, JJU Taylor, J Knauer \& DR Jerry. 2008. Family by environment interactions in shell size of 43-day old silver-lip pearl oyster (Pinctada maxima), five families reared under different nursery conditions. Aquaculture 279: 23-28.

Linard C, Y Gueguen, J Moriceau, C Soyez, B Hui, A Raoux, JP Cuif, JC Cochard, M Le Pennecc \& G Le Moullac. 2011. Calcein staining of calcified structures in pearl oyster Pinctada margaritifera and the effect of food resource level on shell growth. Aquaculture 313(1-4): 149-155.

Lindenmayer M, F Juanes \& M McGinley. 2009. Freshwater mussels in North America, factors affecting their endangerment and extinction. In: Cutler J \& J Cleveland (eds). Encyclopedia of earth. Environmental Information Coalition, National Council for Science and the Environment, Washington, <http://www.eoearth.org/article/ Freshwater_mussels_in_North_America __factors_affecting_their_endangerment_and_extinction>

Mitchell R \& O Baba. 2006. Multi-sector resource allocation and integrated management of abalone stocks in Western Australia: review and discussion of management strategies. Fisheries Science 72(2): 278-288. 
Monteforte M. 2013. Instalación y operación de granjas perleras. Un manual para Pinctada mazatlanica y Pteria sterna, 185 pp. Editorial Académica Española, Lambert Academic Publishing, Saarbrücken.

Monteforte M \& H Bervera. 2010a. Abalone pearl culture on the West Coast of Baja California Peninsula. World Aquaculture Magazine 41(3): 12-17.

Monteforte M \& H Bervera. 2010b. Perlicultura en abulón, Haliotis rufescens, y perspectivas para el desarrollo regional en la costa del Pacífico de la Península de Baja California, México. Panorama Acuícola 16(1): 58-63.

Monteforte M \& H Bervera. 2011. Tecnología de perlicultura en abulón. En: Lira M, C Lodeiros, N González, M ReyMéndez, A Guerra \& J Fernández (eds). III Foro Iberoamericano de los Recursos Marinos y la Acuicultura, pp. 199-208. Fondo Editorial Fundación Sonora, Hermosillo, México.

Monteforte M \& M Cariño. 2011. Maricultura: oportunidad de conversión sustentable para los pescadores ribereños. Revista del Programa de Ciencia, Tecnología e Innovación para el Desarrollo de México, PCTI 3(78). <//pcti.mx/ articulos/item/maricultura-oportunidad-de-conversionsustentable-para-la-pesca-riberena>

Monteforte M \& M Cariño. 2012. Episodes of environmental history in the Gulf of California: fisheries, commerce and aquaculture of nacre and pearls. In: Boyer C (ed). Land between waters: Environmental histories of Western Mexico, pp. 245-276. University of Arizona Press, Tucson.

Monteforte M, P Saucedo \& F Blanc. 1998. Changes in shell dimension during growth of pearl oysters, Pinctada mazatlanica (Hanley 1856) and Pteria sterna (Gould 1851), as criteria for Mabé pearl implants. Aquaculture Research 29: 801-814.

Monteforte M, H Bervera \& P Saucedo. 2004. Response profile of the Calafia pearl oyster, Pinctada mazatlanica (Hanley, 1856), to various sedative therapies related to surgery for round pearl induction. Journal of Shellfish Research 23(1): 121-128.

Müller A. 2005. Cultured pearls: update on global supply, demand and distribution. Presentation at GemmoBasel International Colloquium on Gemmology. April 29-May 2, 2005, Basel, Switzerland. <www.hinatatrading.com/ GemmoBasel.pdf>

Muller A. 2009. A brief analysis of the global seawater cultured pearl industry. Past, present, future, 14 pp. European Gemmological Symposium, Berne, Switzerland, June 5, 2009. < http://www.hinatatrading.com/EGShandout.pdf>

Nava M, E Arizmendi, S Farell \& D McLaurin. 2000. Evaluation of success in the seeding of round nuclei in Pteria sterna (Gould 1851), a new species in pearl culture. SPC Pearl Oyster Information Bulletin 14: 5-7.

Navarrete AJ. 2001. Crecimiento del caracol Strombus gigas (Gastropoda: Strombidae) en cuatro ambientes de Quintana Roo, México. Revista de Biologia Tropical 49(1): 85-91.
Neves R. 2004. Propagation of endangered freshwater mussels in North America. Journal of Conchology, Special Publications Series 3: 69-80.

Ngaluafe P \& PC Southgate. 2008. Winged oyster pearl industry development in Tonga. ACIAR-Papua, New Guinea and Solomon Islands News 5(2): 1-6.

Ogawa J \& JL Corral. 1987. Ensayo de la fijación de semilla del caracol reina Strombus gigas y su crecimiento en un sistema de producción masivo. Proceedings of the ThirtyEighth Annual Gulf and Caribbean Fisheries Institute, Miami, Florida USA, May, 1987, pp. 362-369.

Orcutt E. 1939. Pearls on purpose. The Saturday Evening Post 211(45): 36;96-100;103.

Pagcatipunan A. 1986. Technical assistance on freshwater pearl culture in Bangladesh. FAO Corporate Document Repository, Fisheries and Aquaculture Department. FI:TCP/BGD/4508. Field Document 1. <http:// www.fao.org/docrep/field/003/S2622E/S2622E00.htm>

Pitt JH \& PC Southgate. 2000. When should pearl oyster, Pinctada margaritifera (L.), spat be transferred from the hatchery to the ocean? Aquaculture Research 31: 773-778.

Plagányi EE \& DS Butterworth. 2010. A spatial- and agestructured assessment model to estimate the impact of illegal fishing and ecosystem change on the South African abalone Haliotis midae resource. African Journal of Marine Science 32(2): 207-236.

Ponia B. 2006. Recommendations for regional collaboration in pearl culture, $7 \mathrm{pp}$. Aquaculture Adviser, Secretariat of the Pacific Community, 5th SPC Heads of Fisheries Meeting (3-7th April 2006 Noumea, New Caledonia) Information Paper 1: < http://www.spc.int/DigitalLibrary/Doc/FAME/ Meetings/HOF/5/IP1.pdf $>$

Prince JD. 2004. The decline of global abalone (Genus Haliotis) production in the late twentieth century: is there a future? In: Leber KM, S Kitada, HL Blankenship \& T Svasand (eds). Stock enhancement and sea ranching: Developments, pitfalls \& opportunities, pp. 427-443. Blackwell Publishing, Oxford.

Prince JD. 2005. Combating the tyranny of scale for haliotids: micro-management for micro-stocks. Bulletin of Marine Sciences 72: 557-577.

Rose RA \& SB Baker. 1994. Larval and spat culture of the Western Australian silver-or gold-lip pearl oyster, Pinctada maxima (Jameson) (Mollusca: Pteriidae). Aquaculture 126: 35-50.

Rothaus DP, B Vadopalas \& CS Friedman. 2008. Precipitous declines in pinto abalone (Haliotis kamtschatkana kamtschatkana) abundance in the San Juan Archipelago, Washington, USA, despite statewide fishery closure. Canadian Journal of Fisheries and Aquatic Sciences 65 (12): 2703-2711.

Ruiz-Rubio H, H Acosta-Salmón, A Olivera, PC Southgate \& C Rangel-Dávalos. 2006. The influence of culture method on quality of half-pearls ('mabe') from the winged pearl oyster Pteria sterna, Gould, 1851. Aquaculture 254: 269-274. 
Shor R. 2007. From single source to global free market: the transformation of the cultured pearl industry. Gems \& Gemology 43(3): 200-226.

Southgate P \& J Lucas. 2008. The pearl oysters, 544 pp. Elsevier, Oxford.

Stevens M. 2003. Cultured abalone (Haliotis spp.), 13 pp. Seafood Watch, Seafood Report, Final Report. Monterey Bay Aquarium, Monterey. <http://www.montereybayaquarium.org/cr/ c r_s e a f o od w a t c h/ con t e n t/medi a / MBA_SeafoodWatch_AbaloneFarmedReport.pdf $>$

Straus KM \& CS Friedman. 2009. Restoration aquaculture of the pinto abalone (Haliotis kamtschatkana kamtschatkana Jonas): impacts of rearing method on behaviour, growth and survivorship in the hatchery. Marine and Freshwater Research 60(10): 1021-1028.

Taylor JJ \& E Strack. 2008. Pearl production, pp 273-302. In: Southgate P \& J Lucas (eds). The pearl oyster. Elsevier, Oxford.

Taylor JJ, PC Southgate \& RA Rose. 2004. Effects of salinity on growth and survival of silver-lip pearl oyster, Pinctada maxima, spat. Journal of Shellfish Research 23: 375-377.

Thomas GR, J Taylor \& C García de Leaniz. 2010. Captive breeding of the endangered freshwater pearl mussel, Margaritifera margaritifera. Endangered Species Research 12: 1-9.
Tisdell C \& B Poirine. 2008. Economics of pearl farming, pp. 473-498. In: Southgate P \& J Lucas (eds). The pearl oyster. Elsevier, Oxford.

Ventouras G. 1999. Nuclei alternatives, the future of pearl cultivation. SPC Pearl Oyster Information Bulletin 13: 2526

Victor ACC, A Chellam, S Dharmaraj \& TS Velayudhan. 1995. Manual on pearl oyster seed production, farming and pearl culture. CMFRI, Special Publication 63: 1-60. Manual Series 1.<http://eprints.cmfri.org.in/3482/1/ Special_Publication_No_63.pdf $>$

Wight W. 2008. Scallop pearls from Digby, Nova Scotia. The Canadian Gemmologist 25(1): 18-29.

Yu DH \& KH Chu. 2006. Genetic variation in wild and cultured populations of the pearl oyster Pinctada fucata from southern China. Aquaculture 258: 220-227.

Yuewen D, G Yuanzhen, C Weiyao, D Xiaodong \& L Jing. 2011. Comparison of growth performance and genetic diversity of pearl oyster (Pinctada martensii) families in a breeding program. African Journal of Agriculture Research 6(31): 6530-6536.

Zuhui H \& S Huaping. 2010. Interactive evolution of zhuji pearl industry cluster and specialized market. In: 8th Globelics International Conference. 1-3 November 2010, Kuala Lumpur, Malaysia. Globelics 2010, Paper 156: 110 .

Recibido el 26 de junio de 2012 y aceptado el 30 de enero de 2013

Editor: Claudia Bustos D. 